\title{
PERAN PENDIDIKAN AGAMA ISLAM DALAM MEMBENTUK KARAKTER JUJUR PADA SISWA
}

\author{
Ani Jailani ${ }^{1}$, Chaerul Rochman ${ }^{2}$, dan Nina Nurmila ${ }^{3}$ \\ adejailani91@gmail.com \\ Universitas Islam Negeri Sunan Gunung Djati Bandung ${ }^{1,2,3}$
}

\begin{abstract}
Abstrack
This research was conducted to measure the attitude of honesty in every student in fifth grade elementary school SD.S Plus Syania CImanggung. The method used in this research is the method descriptive quantitative approach. The sample in this study was fifth grade students at SD.S Plus Syania Kel. Cihanjuang Kec. Cimanggung Kab. Sumedang Ansarat. Data collection techniques using observation, this is done by researchers by directly observing the spaciousness as the object of research to obtain data, then researchers provide questionnaires. From the results of the data obtained the average number of honesty attitudes of students in class $V$ amounted to 80.23, a sufficiently large number which means giving the conclusion that the honest attitude of students is quite good and high. This is inseparable from the role of education which always shapes and promotes them in their daily lives, the role of education both in school, family and community environment is a supporting factor in character building or honest attitude towards students
\end{abstract}

Keywords: The Role of Islamic Education, Character, Honest Attitude

\begin{abstract}
Abstrak
Penelitian ini dilakukan untuk mengukur sikap kejujuran pada setiap siswa di kelas V Sekolah Dasar SD.S Plus Syania CImanggung. Metode yang digunakan dalam penelitian ini adalah metode deskriptif dengan pendekatan kuantitatif. Sample pada penelitian ini adalah siswa kelas V di SD.S Plus Syania Kel. Cihanjuang Kec. Cimanggung Kab. Sumedang Jawabarat. Teknik pengumpulan data menggunakan observasi, ini dilakukan oleh peneliti dengan meninjau langsung kelapangan sebagai objek penelitian untuk memperoleh data, kemudian peneliti memberikan kuesioner. Dari hasil data yang diperoleh jumlah rata-rata sikap kejujuran siswa di kelas V sebesar 80.23, jumlah yang cukup besar yang berarti memberikan kesimpulan bahwa sikap jujur yang dimiliki siswa cukup tbaik dan tinggi. Hal ini tidak terlepas dari peran pendidikan yang selalu membentuk dan mengrahkan meraka dalam keseharian mereka, peran pendidikan baik di sekolah, keluarga dan Lingkungan masyarakat menjadi faktor pendukung didalam pembinaan karakter atau sikap jujur terhadap siswa.
\end{abstract}

Kata Kunci: Peranan Pendidikan Agama Islam, Karakter, Sikap Jujur 


\section{PENDAHULUAN}

Dalam upaya mewujudkan tujuan pendidikan nasional, maka sejak tahun 2010 Pemerintah Indonesia berupaya mencanangkan gerakan "Pendidikan Budaya dan Karakter Bangsa”. Untuk mencapai hasil yang maksimal dari gerakan nasional pendidikan budaya dan karakter bangsa tersebut, perlu tindakan pengimplementasian secara sistematis dan berkelanjutan, sebab tindakan implementasi ini akan membangun kecerdasan emosi seorang anak (Wiliandani et al., 2016).

Muatan didalam pendidikan karater ini yang salah satunya adalah kejujuran, didalam prosesnya pemerintah berhraap bisa mendapatkan generasi penerus yang memiliki karater jujur untuk memperbaiki ketimpangan dikalangan masyarakat (Mansyur, 2018). Pendidikan merupakan usaha sadar yang dilakukan manusia dalam menciptakan suasana pembelajaran untuk membentuk dan mengembangkan sikap peserta didik yang sesuai dengan norma yang berlaku, sehingga sekolah dapat berperan sebagai lembaga yang dapat mempersiapkan anak-anak baik secara akademis dan agen moral dalam masyarakat (Mulyadi et al., 2019). Pendidikan sendiri tidak akan lepas dari kehidupan keluarga, sekolah, serta masyarakat (Sada, 2017). Pendidikan merupakan suatu cara dalam meningkatkan kualitas hidup manusia dalam segala aspek kehidupan, misalnya dengan menanamkan akhlak pada manusia (Suryadarma \& Haq, 2015)

Akhlak merupakan suatu kepribadian yang mempunya tiga komponen antara lain pengetahuan, sikap, dan perilaku (Sahlan, 2012). Pendidikan kepribadian atau Akhlak anak merupakan aktivitas untuk mengembangkan segala aspek kepribadian manusia yang berlaku sampai akhir hayat. Dengan demikian Pendidikan kepribadian atau Akhlak anak tidak hanya diruang kelas saja, akan tetapi dapat juga berlangsung diluar kelas. Pendidikan kepribadian atau Akhlak dapat berlangsung dimana dan kapan saja (Sada, 2015)

Dalam upaya untuk memperkuat fungsi dan tujuan pendidikan maka diperlukan Pendidikan Agama Islam (PAI) sebagai harapan untuk membentengi dan mengarahkan para peserta didik dan dapat membentuk sikap dan kepribadian warga negara yang lebih baik. Pada hakiatnya pembelajaran PAI berupaya dan mampu membina akhlak dan menanamkan sikap kejujuran kepada peserta didik, pendidikan agama berupaya terus mambina dan menggali, membentuk dan mengarahkan kepada perbuatan atau akhlak 
terpuji sehingga pendidikan Agama Islam dapat berfungsi sebagai pendidikan karakter. Melalui pendidikan karakter mampu memunculkan kebajikan dari dalam diri seseorang dan mampu memunculkan sikap, nilai dan moral seperti sikap jujur dalam bercakap atau bertindak baik kepada dirinya, kepada orang lain dan kepada tuhannya. Kemudian sikap ini akan terlihat dan muncul dalam tindakan yang nyata yaitu tingkah laku yang baik, jujur, bertanggung jawab, menghormati hak oranglain, kerja keras dan lain sebagainya (Mulyadi et al., 2019).

Winata putra menjelaskan didalam bukunya bahwa karater jujur setiap orang akan menntukan bagaimana terbentuknya identitas suatu bangsa dimasa yang akan datang. Diperlukan usaha dalam pembangnan paradigm pendidikan yang mampu membangun budaya sebagai bagian dari prosespendidikan secara keseluruhan dan proses kehidupan bermasyrakat, berbangsa dan bernegara sebagai suatu keutuhan, maka diperlukan pendidikan yang mampu membina, membentuk dan mengarahkan dan mengutamakan penumbuhan sikap atau karakter jujur kepaada peserta didik (Winataputra, 2012).

Pendidikan karakter haruslah berpijak pada karakter dasar manusia yang bersumber dari nilai moral universal (bersifat absolut) yang bersumber dari agama wahyu yang juga disebut the golden rule (Anwar, 2016). Pendidikan karakter di sekolah merupakan suatu kebutuhan yang sangat penting supaya generasi penerus dapat dibekali dengan kemampuan dasar yang tidak hanya mampu menjadi pembelajaran sepanjang kehidupan sebagai suatu karakter yang penting untuk hidup di era reformasi yang bersifat global, namun dapat berfungsi sebagai peran serta yang positif baik sebagai pribadi, anggota keluarga, warga negara, maupun sebagai warga dunia (Ningsih, 2019).

Pendidikan karakter dapat memiliki tujuan yang pasti, manakala berpijak pada nilai-nilai karakter dasar tersebut. Menurut para psikolog beberapa nilai dasar karakter tersebut adalah cinta kepada Allah dan ciptaan-Nya (alam dan isinya), tanggung jawab, jujur, hormat dan santun, kasih saying, peduli, kerjasama, percaya diri, kreatif, kerja keras dan pantang menyerah, keadilan dan kepemimpinan, baik dan rendah hati, toleransi, cinta damai, dan cinta persatuan (Anwar, 2016) Adapun tujuan pendidikan karakter antara lain: 1) Mengembangkan potensi afektif peserta didik sebagai manusia dan warganegara yang memiliki nilai-nilai karakter bangsa, 2) mengembangkan 
perilaku peserta didik yang terpuji dan sesuai dengan nilai-nilai universal dan tradisi budaya bangsa yang religious, 3) menananmkan jiwa kepemimpinan dan tanggung jawab peserta didik sebagai generasi penerus bangsa, 4) mengembangkan kemampuan peserta didik, serta 5) mengembangkan lingkungan belajar yang aman, jujur, penuh kreativitas, dan persahabatan (Judiani, 2010).

Evaluasi dari Keberhasilan pendidikan karakter ini tentunya tidak dapat dinilai dengan tes formatif atau sumatif yang dinyatakan dalam skor. Tetapi tolak ukur dari keberhasilan pendidikan karakter adalah terbentuknya peserta didik yang berkarakter; berakhlak, berbudaya, santun, religius, kreatif, inovatif yang teraplikasi dalam kehidupan disepanjang hayatnya. Oleh karena itu tentu tidak ada alat evaluasi yang tepat dan serta merta dapat menunjukkan keberhasilan pendidikan karakter (Ainiyah, 2013)

Hal ini menjadi jelas bahwa sekolah sebagai lembaga penyelenggara pendidikan melalui Pendidikan Agama Islam dituntut untuk mampu memberikan pendidikan, pembunaan dan pembiasaan terhadap prilaku jujur kepada setiap peserta didiknya. Pendidikan karakter ini bukan suatu perkara yang mudah akan tetapi memerlukan waktu, usaha dan kerjakeras dari para pendidiknya. Maka dari itu sangat jelas bahwa dalam pendidikan karakter perlu kerja keras dan kerjasama semua pihak baik guru sebagai pendidik, juga peserta didik dan Orangtua untuk ikut dalam menciptakan pendidikan karakter yang secara efektif agar mampu menghasilkan pendidikan yang berkualitas serta didukung oleh pembelajaran yang berkualitas maka akan menjadi unggul dan lebih baik (Raharjo, 2010).

Adapun kendala-kendala didalam penerapan pembinaan Sikap Kejujuran didalam pembelajaran Pendidikan Agama Islam (a) faktor guru, guru mengalami kesulitan dalam menentukan materi yang sesuai dengan nilai kejujuran yang telah diintegrasikan, dan keterbatasan waktu pembelajaran; (b) faktor siswa, pemahaman siswa yang salah terhadap kebiasaan yang dianggap lumrah atau wajar dalam bersikap tidak jujur; (c) faktor lingkungan, pengaruh negatif dari lingkungan siswa. Lingkungan tempat tinggal siswa sangat mempengaruhi perilaku siswa. Teman yang baik akan membawa perilaku yang baik pada diri individu begitu juga sebaliknya. 
Dari pemaparan diatas maka diperlukan lah sebuah tujuan, visi dan misi lembaga pendidikan yang jelas untuk menciptakan dan mebentuk karakter peserta didik dalam lingkungan sekolah yang kemudian dilaksanakan melalui program-progran kegiatan sekolah. Maka dari itu atas latar belakang penjelasan diatas maka penulis tertarik untuk menelaah lebih dalam tentang peran dari Pendidikan Agama Islam dalam Membentuk Karakter jujur pada Siswa.

\section{METODE PENELITIAN}

Penelitian ini dilakukan di SD.S Plus Syania Perum SBG Parakan Muncang Kel. Cihanjuang Kec. Cimanggung Kab. Sumedang Jawabarat. Adapun Metode yang digunakan dalam penelitian ini adalah metode deskriptif dengan pendekatan kuantitatif. Instrument yang digunakan peneliti adalah kuisioner sample pada penelitian ini adalah siswa kelas V di SD.S Plus Syania Kel. Cihanjuang Kec. Cimanggung Kab. Sumedang Jawabarat. Teknik pengumpulan data menggunakan observasi, ini dilakukan oleh peneliti dengan meninjau langsung kelapangan sebagai objek penelitian untuk memperoleh data, kemudian peneliti memberikan kuesioner kepada responden yang kemudian hasilnya menjadi data yang akan di olah dan di analisis untuk tahap berikutnya, teknik ini digunkan untuk memperoleh data cecara langsung kepada responden untuk memperoleh data yang akurat dan, analisis data, bertujuan untuk mengolah data hasil temuan untuk ditarik menjadi sebuah kesimpulan penelitian.

\section{HASIL PENELITIAN DAN PEMBAHASAN}

Peran pendidikan Islam sangat dibutuhkan dalam mendukung pembentukan karakter Jujur dimanan menjadi era yang penuh tantangan dihadapi oleh para siswa saat ini, para siswa menjadi bingung dan bertanya-tanya mereka harus melkukan apadan baimana harus bersikap. Melalui Pendidikan Agama Islam siswa-siswa dapat memiliki bekal untuk memiliki karakter jujur dalam kehidupan sehari-hari. (Ningsih, 2019). Peran Penididikan Agama Islam sama dengan peran Pendidikan kepribadian atau Akhlak adalah membentuk manusia berakhlak mulia, yaitu suatu keadaan yang melihat pada diri manusia tanpa melalui proses perhitungan, pemikiran dan penelitian yang menimbulkan hal yang baik yang disebut karakter jujur. (Sada, 2015) 
Berdasarkan kuesioner yang di kembangkan kemudian data yang diperoleh diolah dan di analisis dan di sajikan didalam table berikut ini.

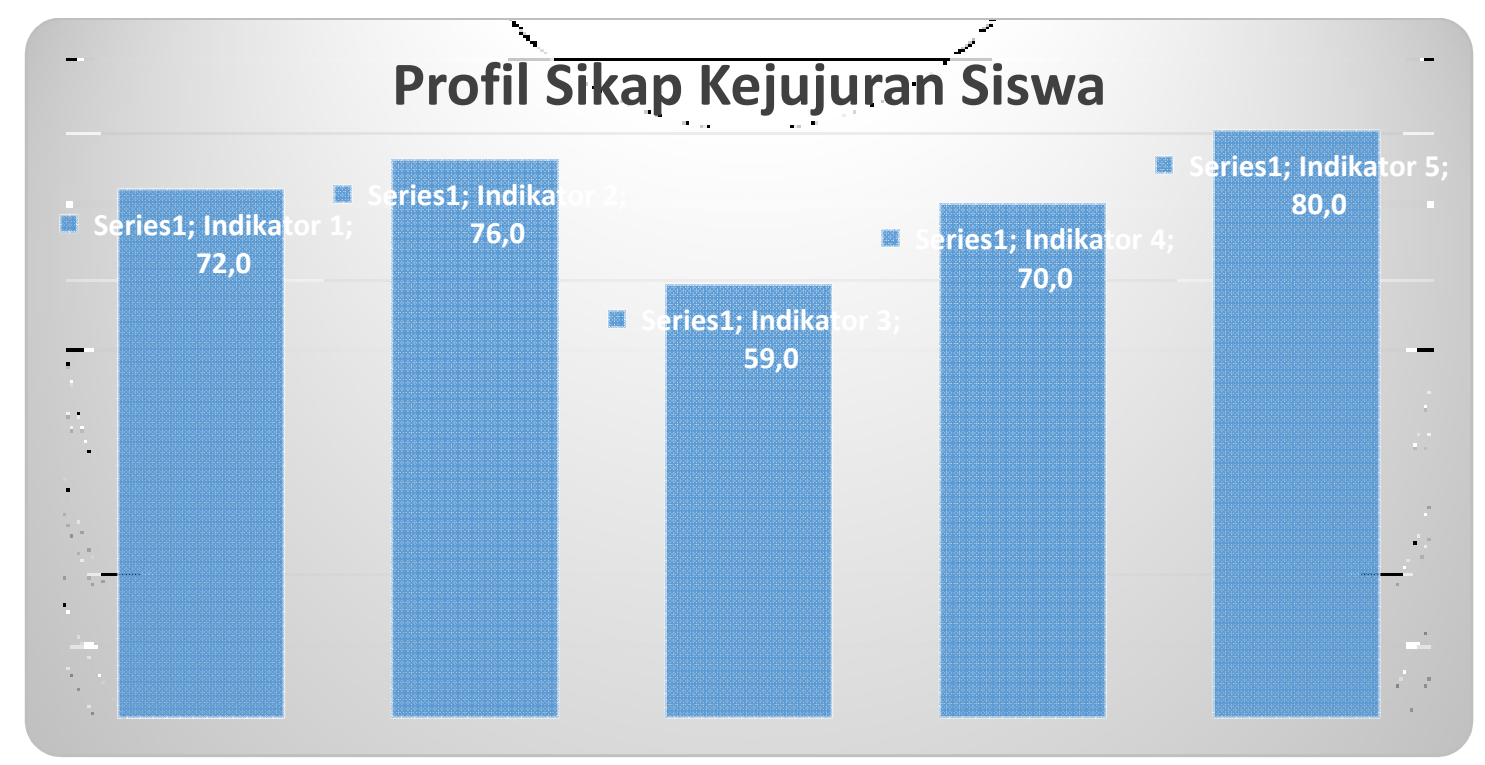

Grafik 1 menunjukan pencapaian sikap kejujuran siswa kelas V Isi SD.S Plus Syania Kec. Cimanggung Kab. Sumedang Jawa Barat.

Dari kelima indikator yang dikembangkan yang kemudian data yang diperoleh kemudian dianalisis, menunjukan bahwa sikap kejujuran siswa bisa dikatan cukup baik walaupun masih terdapat kekurangan dari indicator ke 3 yang dikembangkan. Kekurangan pada indikator ke 3 terletak kepada kelemahan siswa dalam mengutarakan alasan terhadap pilihan nya, walaupun sebenarnya respon meraka cukup baik dalam menanggapi pertanyaan yang di sajikan dalam indicator ke 3 .

Perolehan yang cukup tinggi terjadi pada indicator ke 5, dimana siswa diminta untuk menunjukan sikap yang mereka rasakan jika berbuat suatu kebohongan, mereka menanggapi cukup beragam yang intinya mereka merasakan ketidak nyamanan dalam diri mereka ketika melakukukan sebuah kebohongan, ini artinya sikap kejujuran sudah mulai tertanam dalam jiwanya.

Pada indikator yang lainnya pun mendapatkan nilain yang cukup bagus, artinya siswa sudah memahami dan mulai menerapkan prilaku jujur ini didalam kehudupan meraka sehari-hari. Berdasarkan analisis data diatas penanaman sikap jujur sudah berjalan dengan baik dan diterima dengan baik oleh para peserta didik.

Berikut grafik pencapaian setiap responden: 


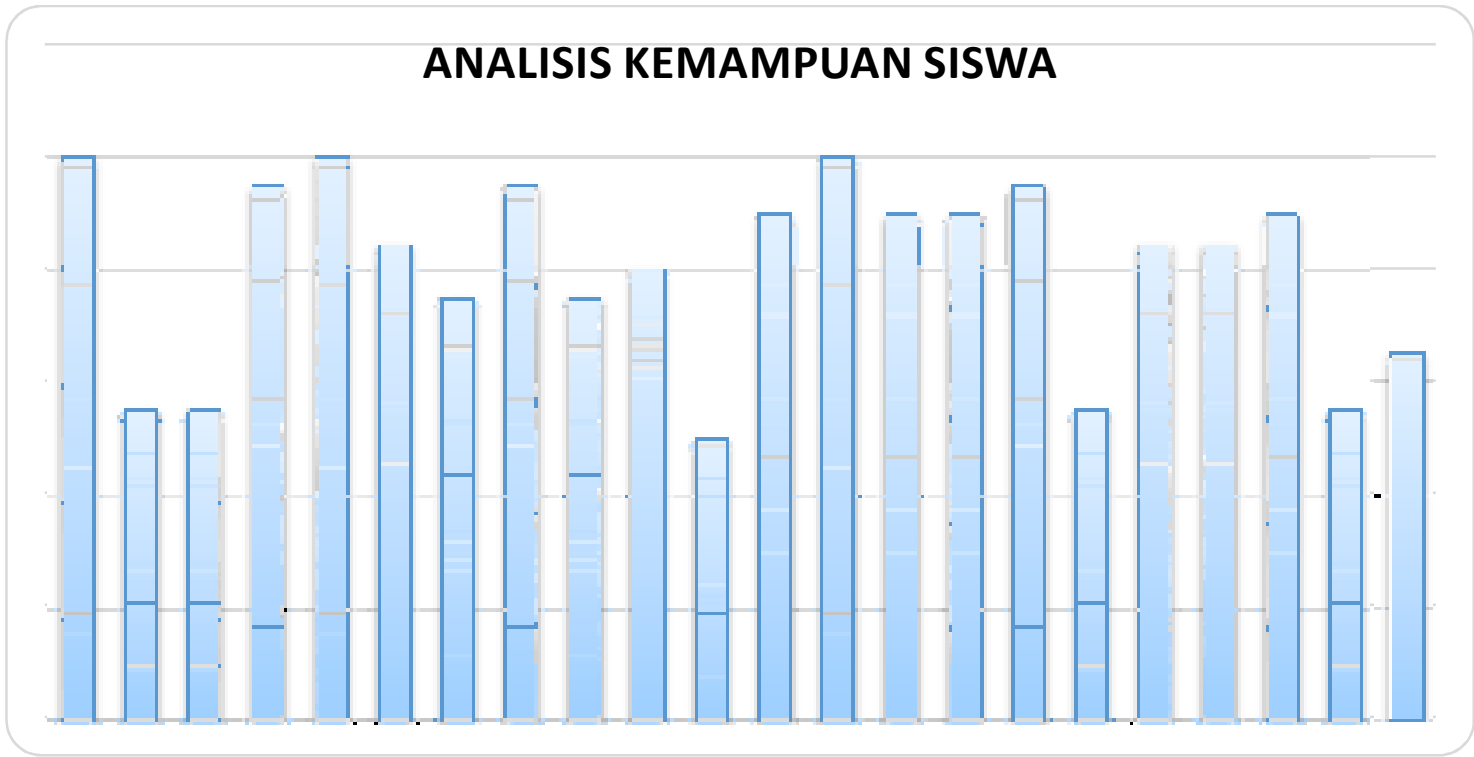

Grafik 2 menunjukan tingkat kemampuan responden didalam bersikap jujur

Dari data diatas perolehan rata-rata kemampuan siswa sebesar 80.23 hal ini bisa dikatakan kejujuran pada setiap siswa tertanam cukup baik, siswa cenderung memberikan respon positif terhadap prilaku kejujuran mereka, hal ini menjadi bagian dari peranan pendidikan Agama yang diterima dengan baik baik didalam lingkungan sekolah, keluarga dan lingkungan masyarakat.

\section{SIMPULAN DAN SARAN}

Dari hasil data yang diperoleh rata-rata pemahan yang diperoleh dari siswa tentang sikap kejujuran dengan jumlah rata-rata 80.23 hal ini menunjukan bahwa tingginya nilai kejujuran yang dimiliki setiap siswa. Besaran perolehan persentase masing-masing indikator cenderung relative tinggi, walaupun pada indikator 3 dimana mereka masih merasa kesulitan dalam mengutarakan pendapatnya ketika mereka menghadapi atau menemukan prilaku sikap ketidak jujuran dan kebohongan. Perolehan tinggi pada indikator 5 yang di kuat kan oleh pernyataan mereka tentang sikap meraka yang cenderung menolak terhadap ketidak jujuran, pernyataan mereka menjelaskan bahwa tingkat kejujuran yang tinggi yang dimiliki oleh setiap siswa di kelas V SD.S Plus Syania Cimanggung. Bagi peneliti selanjutnya hendaknya bisa lebih baik lagi dalam menumbuhkan karakter jujur pada siswa. 


\section{DAFTAR PUSTAKA}

Ainiyah, N. (2013). Pembentukan Karakter Melalui Pendidikan Agama Islam. Jurnal Al-Ulum, 13(1), 25-38.

Anwar, S. (2016). Peran Pendidikan Agama Islam dalam Membentuk Karakter Bangsa. Al-Tadzkiyyah: Jurnal Pendidikan Islam, 7, 157-169.

Judiani, S. (2010). Implementasi Pendidikan Karakter di Sekolah Dasar melalui Penguatan Pelaksanaan Kurikulum. Jurnal Pendidikan Dan Kebudayaan, 16, 280-289.

Mansyur, U. (2018). Pemanfaatan Nilai Kejujuran dalam Cerpen sebagai Bahan Ajar Berbasis Pendidikan Karakter. INA-Rxiv.

Mulyadi, D., Sapriya, \& Rahmat. (2019). Kajian Tentang Penumbuhan Karakter Jujur Peserta Didik Sebagai Upaya Pengembangan Dimensi Budaya Kewarganegaraan (Civic Culture) di Sma Alfa Centauri Bandung. MODELING : Jurnal Program Studi PGMI, 6(2), 220-232.

Ningsih, T. (2019). Peran Pendidikan Islam dalam Membentuk Karakter Siswa di Era Revolusi Industri 4.0 pada Madrasah Tsanawiyah 1 Banyumas. Insania, 24(2).

Raharjo, S. B. (2010). Pendidikan Karakter sebagai Upaya Menciptakan Akhlak Mulia. Jurnal Pendidikan Dan Kebudayaan, 16(3), 229-238.

Sada, H. J. (2015). Konsep Pembentukan Kepribadian Anak dalam Perspektif AlQur'an (Surat Luqman Ayat 12-19). Al-Tadzkiyyah: Jurnal Pendidikan Islam, 6(2), 252-272.

Sada, H. J. (2017). Peran Masyarakat dalam Pendidikan Perspektif Pendidikan Islam. Al-Tadzkiyyah: Jurnal Pendidikan Islam, 8(1), 117-125.

Sahlan, A. (2012). Pendidikan Karakter dalam Perspektif Islam (Kajian Penerapan Pendidikan Karakter di Lembaga Pendidikan Islam). Jurnal El-Hikmah: Jurnal Kependidikan Dan Keagamaan, 139-149.

Suryadarma, Y., \& Haq, A. H. (2015). Pendidikan Akhlak Menurut Imam Al-Ghazali. Jurnal At-Ta'dib, 10(2).

Wiliandani, A. M., Wiyono, B. B., \& Sobri, A. Y. (2016). Implementasi Pendidikan Karakter dalam Pembelajaran di Sekolah Dasar. Jurnal Pendidikan Humaniora, $4(3), 132-142$.

Winataputra. (2012). Pendidikan Kewarganegaraan dalam Perspektif Pendidikan untuk Mencerdaskan Kehidupan Bangsa: Gagasan, Instrumental, dan Praksis. Widya Aksara Press. 